LETTER TO JMG

\title{
High incidence of skewed $X$ chromosome inactivation in young patients with familial non-BRCA1/BRCA2 breast cancer
}

\author{
M Kristiansen, G P S Knudsen, P Maguire, S Margolin, J Pedersen, A Lindblom, K H Ørstavik
}

J Med Genet 2005;42:877-880. doi: 10.1136/jimg.2005.032433

Background: A higher frequency of skewed X chromosome inactivation has been reported in a consecutive series of young patients with breast cancer compared with controls of a similar age.

Objective: To investigate the $X$ inactivation pattern in patients with familial non-BRCA1/BRCA2 breast cancer $(n=272)$, $B R C A 1 / B R C A 2$ germline mutations $(n=35)$, and sporadic breast cancer $(\mathrm{n}=292)$.

Methods: X inactivation pattern was determined by polymerase chain reaction analysis of the highly polymorphic CAG repeat in the androgen receptor $(A R)$ gene. The $X$ inactivation pattern was classified as skewed when $90 \%$ or more of the cells preferentially expressed one $X$ chromosome. Results: Young patients with familial breast cancer had a significantly higher frequency of skewed $\mathrm{X}$ inactivation $(11.2 \%)$ than young controls $(2.7 \%)(p=0.001)$. There was also a strong tendency for middle aged patients with sporadic breast cancer to be more skewed than middle aged controls (13.6\% v 4.4\%) $(p=0.02)$. No association between skewed $X$ inactivation and breast cancer was found for the $B R C A 1 / B R C A 2$ patients

Conclusions: Skewed $\mathrm{X}$ inactivation may be a risk factor for the development of breast cancer in both sporadic and familial breast cancer and may indicate an effect of $X$ linked genes.

O ne of the two $\mathrm{X}$ chromosomes in female mammalian cells is inactivated in early embryonic life. Females are therefore mosaics for two different cell types, cells with the paternal $X$ chromosome as the active $X$, and cells with the maternal $\mathrm{X}$ chromosome as the active $\mathrm{X} .{ }^{1}$ In young females, the distribution of the two cell lines is close to normal, with a mode corresponding to the 50:50 ratio. Skewed X inactivation is a marked deviation from the 50:50 ratio and may be due to chance, to genetic factors involved in the $\mathrm{X}$ inactivation process, or to a selection process. ${ }^{2-4}$ Elderly females have an increased frequency of skewed $X$ inactivation in peripheral blood cells, most probably also reflecting a selection process. ${ }^{56}$

Breast cancer results from genetic and environmental factors causing accumulation of mutations and eventually cancer. Germline mutations in BRCA1 and BRCA2 account for $15-20 \%$ of familial breast cancer, but less than $5 \%$ of all breast cancers. ${ }^{78}$ In a study of patients with ovarian cancer, a higher frequency of skewed $X$ inactivation was found in patients with invasive cancer compared with those with borderline cancer and healthy controls. ${ }^{9}$ We have reported an association between skewed $\mathrm{X}$ inactivation and breast cancer in young patients. ${ }^{10}$ The patients were part of a consecutive series with no information on family history or mutation analysis. Of this consecutive series approximately 30\% are expected to have a positive family history. ${ }^{11}$ It was therefore of interest to analyse $X$ inactivation in subsets of patients with breast cancer. In this report we describe the results of $X$ inactivation analysis of 272 patients with familial breast cancer, 35 with BRCAl/BRCA2 germline mutations, and 292 with sporadic breast cancer.

\section{METHODS}

\section{Breast cancer cases}

Blood samples from the patients had been collected after informed consent at Karolinska Hospital (material 1) and Huddinge Hospital and Söder Hospital (material 2) in Stockholm between 1989 and 2000. Material 1 was collected at a hospital where patients are referred for genetic counselling because of an increased risk of breast cancer. These patients were screened for both BRCA1 and BRCA2 mutations. ${ }^{12-15}$ Material 2 was a consecutive series of breast cancer patients collected at surgery. These patients were screened for mutations in BRCAl exon 11 only, as the previous studies from the Stockholm region showed that $70 \%$ of the BRCAl mutations were detected in exon $11 .{ }^{12} 1415$ Furthermore, the estimated BRCAl mutation frequency in an unselected breast cancer population from this region is less than $1 \%{ }^{16}$ and mutations in BRCA2 are even less frequent. ${ }^{13} 15$ Blood samples were drawn on average five years after onset. The study was approved by the ethics committee at the Karolinska Institutet.

Familial cases (from materials 1 and 2)

The patients were 306 women with non-BRCA1/BRCA2 breast cancer. Of these, 183 were low risk patients with one close (first or second degree) relative with breast cancer, and 123 were high risk patients with two or more close relatives with breast cancer.

$B R C A 1 / B R C A 2$ mutation cases (from material 1) The patients were 31 women with a BRCAl mutation and eight with a BRCA2 mutation.

\section{Sporadic cases (from material 2)}

The patients were 322 women without a family history of breast cancer.

\section{Controls}

The controls were previously analysed women. As skewing of $\mathrm{X}$ inactivation increases after the age of about 55 years, ${ }^{17}$ it was necessary to have controls of different age groups. Young controls were 259 women from two populations of blood donors aged 20 to $54 . .^{10}$ Middle aged controls were a population of 91 women aged 55 to 72 years, who were part of a routine mammography screening programme where 
Table 1 Frequency of skewed $X$ inactivation ( $\geqslant 90: 10)$ in patients with breast cancer

\begin{tabular}{|c|c|c|c|c|c|c|c|c|c|}
\hline & \multicolumn{9}{|c|}{ Age group (years) } \\
\hline & \multicolumn{3}{|l|}{$<55$} & \multicolumn{3}{|l|}{$55-72$} & \multicolumn{3}{|l|}{$>72$} \\
\hline & No/total & (\%) & p Value* & No/total & (\%) & p Value* & No/total & (\%) & p Value* \\
\hline \multicolumn{10}{|l|}{ Patients } \\
\hline Familial†ł & $12 / 107$ & $(11.2)$ & 0.001 & $11 / 113$ & (9.7) & 0.15 & $4 / 52$ & (7.7) & 0.02 \\
\hline Low risk† & $10 / 76$ & (13.2) & 0.001 & $7 / 65$ & (10.8) & 0.22 & $1 / 29$ & (3.4) & 0.02 \\
\hline Low risk† & $6 / 32$ & (18.8) & 0.001 & $3 / 26$ & (11.5) & 0.18 & $0 / 12$ & $(0.0)$ & 0.16 \\
\hline Low risk‡ & $4 / 44$ & $(9.1)$ & 0.06 & $4 / 39$ & (10.3) & 0.38 & $1 / 17$ & (5.9) & 0.23 \\
\hline High risk†‡ & $2 / 31$ & (6.5) & 0.25 & $4 / 48$ & (8.3) & 0.57 & $3 / 23$ & (13.0) & 0.51 \\
\hline High risk† & $2 / 20$ & $(10.0)$ & 0.13 & $2 / 34$ & (5.9) & 0.66 & $1 / 19$ & (5.3) & 0.17 \\
\hline High riskł & $0 / 11$ & $(0.0)$ & 1.00 & $2 / 14$ & (14.3) & 0.18 & $2 / 4$ & $(50.0)$ & 0.21 \\
\hline $\mathrm{BRCAl} / 2 \dagger$ & $1 / 24$ & (4.2) & 0.51 & $1 / 11$ & $(9.1)$ & 0.44 & & & \\
\hline Sporadicf & $6 / 97$ & (6.2) & 0.21 & $18 / 132$ & (13.6) & 0.02 & $10 / 63$ & (15.9) & 0.35 \\
\hline Controls & $7 / 259$ & $(2.7)$ & & $4 / 91$ & (4.4) & & $43 / 202$ & (21.3) & \\
\hline \multicolumn{10}{|c|}{$\begin{array}{l}\text { Probability (p) values } \leqslant 0.06 \text { are in bold. Low risk patients were patients with one close relative (first or second degree) with breast cancer; high risk patients were } \\
\text { those with two or more close relatives with breast cancer. } \\
\text { ×Patients were compared with controls of their respective age group; } p \text { values } \leqslant 0.017 \text { are significant (after Bonferroni correction). } \\
\text { †Patients from Karolinska Hospital. } \\
\text { †Patients from Huddinge Hospital and Söder Hospital. }\end{array}$} \\
\hline
\end{tabular}

blood samples were collected after two negative screenings. ${ }^{10}$ Elderly controls were 202 dizygotic twins aged 73 to 93 years. ${ }^{10}$

\section{$X$ chromosome inactivation analysis}

DNA was extracted from peripheral blood cells according to standard procedure. The $\mathrm{X}$ inactivation pattern was determined by polymerase chain reaction (PCR) analysis of a polymorphic CAG repeat in the first exon of the androgen receptor $(A R)$ gene. ${ }^{19}$ Methylation of HpaII sites in close proximity to this repeat correlates with $\mathrm{X}$ chromosome inactivation. After digestion with the methylation sensitive enzyme HpaII, a PCR product is obtained from the inactive $\mathrm{X}$ chromosome only. Additionally, PCR amplification of a segment in exon 1 of the pseudoautosomal MIC2 gene was carried out on both undigested and digested samples to control for completeness of digestion. ${ }^{20}$ MIC2 is unmethylated on both the active and inactive X chromosome, and no PCR product is expected from completely digested samples. ${ }^{21}$ PCR products from undigested and digested DNA were separated on an ABI 3100 automated sequencer, and analysed by GeneScan software (Applied Biosystems, Foster City, California, USA).

The $\mathrm{X}$ inactivation pattern was recorded as the relative amount of the PCR product of the smallest allele. The pattern was classified as skewed when $90 \%$ or more of the cells preferentially expressed one X chromosome.

\section{Statistical methods}

The Pearson $\chi^{2}$ test was used for testing categorical variables. The Fisher two tailed exact test was used where appropriate. As we divided the patients into three groups according to their ages, the probability (p) value to reach statistical significance was set at 0.017 (Bonferroni correction).

\section{RESULTS}

\section{Patients with a family history of breast cancer}

Of the 306 patients with familial non-BRCA1/BRCA2 breast cancer, 272 were heterozygous for the CAG repeat in the $A R$ gene and were therefore informative for the $\mathrm{X}$ inactivation assay. When the total material of familial cases, including both low risk and high risk cases, was compared with controls in the respective age groups, a significantly higher frequency of skewed $\mathrm{X}$ inactivation was found in young patients (27 to 54 years) compared with young controls $\left(11.2 \%\right.$ and $2.7 \%$ respectively; $\left.\chi^{2}=11.15, p=0.001\right)($ table 1$)$.
The frequency of skewed $X$ inactivation in the total material of young low risk patients $(13.2 \%)$ was significantly higher than in controls of similar age $\left(2.7 \% ; \chi^{2}=11.25, \mathrm{p}=0.001\right)$. There was some discrepancy between the two materials of young low risk patients with respect to skewing of $\mathrm{X}$ inactivation, patients from material 1 being more skewed than those from material 2. However, both materials showed a distinct difference in $\mathrm{X}$ inactivation skewing compared with controls. Young high risk patients were also more skewed than young controls, but the difference was not significant $(6.5 \%$ and $2.7 \%$, respectively; Fisher's exact test, $\mathrm{p}=0.25)$.

Information on the absence of breast cancer after mammography screening was available in the controls aged 55 to 72 years only. When this group was compared with the total material of familial cases in the same age group, a difference in the frequency of skewed $\mathrm{X}$ inactivation was also found $(4.4 \%$ and $9.7 \%$, respectively), but this was not significant $\left(\chi^{2}=2.11, \mathrm{p}=0.15\right)$. Middle aged low risk and high risk patients were also more skewed than controls, but the differences were not significant.

The elderly patients had a lower, and close to significant, frequency of skewed $\mathrm{X}$ inactivation than elderly controls $\left(\chi^{2}=5.07, p=0.02\right)$. A lower frequency of skewed $X$ inactivation was also observed for elderly low risk and high risk patients, but neither was significantly different from controls.

\section{Patients with BRCA germline mutations}

Twenty seven patients with a BRCAl mutation and eight with a BRCA2 mutation were informative for $\mathrm{X}$ inactivation analysis. Only one young and one middle aged patient had a skewed $X$ inactivation pattern, which was not significantly different from the frequency in the controls of the same age groups (table 1).

\section{Patients with sporadic breast cancer}

Of 322 patients with sporadic breast cancer, 292 were informative for $\mathrm{X}$ inactivation analysis. There was no significant difference between young patients and young controls with respect to $\mathrm{X}$ inactivation skewing $(6.2 \%$ and $2.7 \%$, respectively) (table 1 ). There was, however, a strong tendency for middle aged patients ( 55 to 72 years) to be more skewed than middle aged controls (13.6\% $v 4.4 \%$, respectively) $\left(\chi^{2}=5.17, \mathrm{p}=0.02\right)$. 


\section{DISCUSSION}

We found a higher frequency of skewed $\mathrm{X}$ inactivation in young patients $(<55$ years) with familial non-BRCAl/BRCA2 breast cancer than in young controls $(\mathrm{p}=0.001)$ (table 1 ). Young low risk patients were significantly more skewed in $\mathrm{X}$ inactivation than young controls. The same association was not found for the high risk patients. However, the number of young high risk patients was only 31 , and the low frequency of patients with skewed $X$ inactivation may therefore reflect statistical fluctuation and requires further study.

Middle aged patients ( 55 to 72 years) with sporadic breast cancer also had a higher frequency of skewed $\mathrm{X}$ inactivation than middle aged controls, though this did not reach significance $(p=0.02$; table 1$)$. In a previous study we found an increased frequency of skewed $X$ inactivation in a consecutive series of young breast cancer patients with no available information on family history or mutation analysis. ${ }^{10}$ Our current findings indicate that skewed $\mathrm{X}$ inactivation may be a risk factor in both sporadic and familial breast cancer. One explanation could be that some of the familial cases are carriers of a mutation in an $\mathrm{X}$ linked tumour suppressor gene. An additional preferential inactivation of the normal X chromosome could lead to early onset of breast cancer. In the haematopoietic stem cells of the sporadic cases, a mutation during early years in an $\mathrm{X}$ linked tumour suppressor gene on the active $\mathrm{X}$ chromosome could lead to a selective growth advantage for the mutation carrying blood cells. As a result, skewed $\mathrm{X}$ inactivation may become apparent at middle age or older. Thus a mutated X linked factor that confers a growth advantage to blood cells may also be involved in sporadic breast carcinogenesis-for example, as an angiogenetic factor. Another explanation could be that in some females who are born with skewed X inactivation cells are expressing a factor that is harmless to young females but which confers damage to breast epithelia owing to the hormonal changes after the menopause.

Elderly healthy women have an increased frequency of skewed $X$ inactivation in their peripheral blood cells. This increase in frequency seems to occur after the age of 55 years and continues throughout life. ${ }^{517}$ In this study we found an unexpected lack of increased frequency of skewed $\mathrm{X}$ inactivation with age in the familial breast cancer cases, as $7.7 \%$ of the elderly patients had skewed $X$ inactivation compared with $21 \%$ of elderly controls (table 1 ). A lower frequency of skewed X inactivation (14\%) was also observed in elderly subjects in our previous study of a consecutive series of breast cancer patients. ${ }^{10}$ This is in contrast to our finding in a series of patients with cervical cancer, where the same increase in skewing was found both in elderly patients and controls (23\% and $21 \%$, respectively). ${ }^{22}$ Thus skewed X inactivation may be a risk factor for the development of breast cancer in young women with a family history of breast cancer, while the older patient group may be protected by the lack of $X$ inactivation skewing. A discrepancy between early and late onset of breast cancer in this respect may also reflect different genetic backgrounds or tumour pathways between these two kinds of breast cancer.

Buller and coworkers ${ }^{9}$ found a skewed $\mathrm{X}$ inactivation $(\geqslant 75: 25)$ in nine of 11 patients with ovarian cancer where a BRCAl mutation was identified. It is suggested that the $\mathrm{BRCAl}$ protein is involved in maintaining the inactive $\mathrm{X}$ chromosome in the inactive state through XIST RNA localisation. ${ }^{23}$ It was therefore of interest to look for an association between patients with BRCA mutations and X inactivation skewing. We did not find a significant increase in frequency of skewed $\mathrm{X}$ inactivation in the BRCAl/BRCA2 breast cancer patients. However, the number of patients was very small, and an association between skewed $\mathrm{X}$ inactivation and cancer in the BRCAI/BRCA2 patients cannot be excluded.
Information on the timing of blood sampling in relation to treatment was not available for the patients in this study. There is a possibility that chemotherapy may cause neutropenia and lymphopenia which could lead to skewed $\mathrm{X}$ inactivation. However, no change in $\mathrm{X}$ inactivation pattern was seen in patients who had received chemotherapy a year after treatment in a study by Buller and coworkers. ${ }^{9}$

In summary, we have found a higher frequency of skewed $\mathrm{X}$ inactivation in young patients with familial non-BRCAI/ $B R C A 2$ breast cancer and in middle aged patients with sporadic breast cancer. This indicates that skewed $\mathrm{X}$ inactivation may be a risk factor for the development of breast cancer and could indicate an effect of X linked genes.

\section{ACKNOWLEDGEMENTS}

This work was supported by the Research Council of Norway, The Norwegian Cancer Society, and the Swedish Cancer Society.

\section{Authors' affiliations}

M Kristiansen, G P S Knudsen, J Pedersen, Faculty Division

Rikshospitalet, University of Oslo, Oslo, Norway

P Maguire, A Lindblom, Department of Molecular Medicine, Karolinska Institutet, Stockholm, Sweden

S Margolin, Department of Oncology, Karolinska University Hospital at Södersjukhuset, Stockholm, Sweden

K H Ørstavik, Department of Medical Genetics, Rikshospitalet, Oslo

Competing interests: none declared

Correspondence to: Professor Karen Helene Ørstavik, Department of Medical Genetics, Rikshospitalet, 0027 Oslo, Norway; k.h.orstavik@ medisin.vio.no

Received 1 March 2005

Revised version received 4 April 2005

Accepted for publication 8 April 2005

\section{REFERENCES}

1 Lyon MF. Gene action in the X-chromosome of the mouse (Mus musculus L). Nature 1961;190:372-3.

2 Puck JM, Willard HF. X inactivation in females with X-linked disease. N Engl J Med 1998;338:325-8.

3 Belmont JW. Genetic control of $X$ inactivation and processes leading to $X$ inactivation skewing. Am J Hum Genet 1996;58:1101-8.

4 Brown CJ, Robinson WP. The causes and consequences of random and nonrandom X chromosome inactivation in humans. Clin Genet 2000;58:353-63.

5 Busque L, Mio R, Mattioli J, Brais E, Blais N, Lalonde Y, Maragh M, Gilliland DG. Nonrandom X-inactivation patterns in normal females: lyonization ratios vary with age. Blood 1996;88:59-65.

6 Christensen K, Kristiansen M, Hagen-Larsen H, Skythe A, Bathum L, Jeune B, Andersen-Ranberg K, Vaupel JW, Orstavik KH. X-linked genetic factors regulate hematopoietic stem-cell kinetics in females. Blood 2000;95:2449-51.

7 Couch FJ, DeShano ML, Blackwood MA, Calzone K, Stopfer J, Campeau L, Ganguly A, Rebbeck T, Weber BL. BRCA1 mutations in women attending clinics that evaluate the risk of breast cancer. N Engl J Med 1997;336: 1409-15.

8 Peto J, Collins N, Barfoot R, Seal S, Warren W, Rahman N, Easton DF, Evans C, Deacon J, Stratton MR. Prevalence of BRCA1 and BRCA2 gene mutations in patients with early-onset breast cancer. J Natl Cancer Inst 1999:91:943-9.

9 Buller RE, Sood AK, Lallas T, Buekers T, Skilling JS. Association between nonrandom X-chromosome inactivation and BRCA1 mutation in germline DNA of patients with ovarian cancer. J Natl Cancer Inst 1999;91:339-46.

10 Kristiansen M, Langerød A, Knudsen GP, Weber BL, Børresen-Dale AL, Orstavik $\mathrm{KH}$. High frequency of skewed $\mathrm{X}$ inactivation in young breast cancer patients. J Med Genet 2002;39:30-3.

11 Nathanson KN, Wooster R, Weber BL. Breast cancer genetics: what we know and what we need. Nat Med 2001;7:552-6.

12 Zelada-Hedman M, Wasteson Arver B, Claro A, Chen J, Werelius B, Kok H, Sandelin K, Hakansson S, Andersen TI, Borg A, Borresen Dale AL, Lindblom A. A screening for BRCA1 mutations in breast and breast-ovarian cancer families from the Stockholm region. Cancer Res 1997;57:2474-7.

13 Chen J, Hedman MZ, Arver BW, Sigurdsson S, Eyfiord JE, Lindblom A. BRCA2 germline mutations in Swedish breast cancer families. Eur J Hum Genet 1998;6:134-9.

14 Arver B, Claro A, Langerod A, Borresen-Dale AL, Lindblom A. BRCA1 screening in patients with a family history of breast or ovarian cancer. Genet Test 1999;3:223-6.

15 Arver B, Borg A, Lindblom A. First BRCA1 and BRCA2 gene testing implemented in the health care system of Stockholm. Genet Test 2001;5:1-8. 
16 Margolin S, Werelius B, Fornander T, Lindblom A. BRCA1 mutations in a population-based study of breast cancer in Stockholm County. Genet Test 2004;8:127-32

17 Kristiansen M, Knudsen GPS, Bathum L, Naumova A, Sorensen TI, Brix TH, Svendsen AJ, Kyvik KO, Orstavik KH. Twin study of genetic and aging effects on X chromosome inactivation. Eur J Hum Genet 2005; 13:599-606.

18 Orstavik KH, Orstavik RE, Naumova AK, D'Adamo P, Gedeon A, Bolhuis PA, Barth PG, Toniolo D. X chromosome inactivation in carriers of Barth syndrome. Am J Hum Genet 1998;63:1457-63.

19 Allen RC, Zoghbi HY, Moseley AB, Rosenblatt HM, Belmont JW. Methylation of Hpall and Hhal sites near the polymorphic CAG repeat in the human androgen-receptor gene correlates with $X$ chromosome inactivation. Am J Hum Genet 1992:51:1229-39.
20 Anderson CL, Brown CJ. Variability of $X$ chromosome inactivation: effect on levels of TIMP1 RNA and role of DNA methylation. Hum Genet 2002;110:271-8.

21 Goodfellow PJ, Mondello C, Darling SM, Pym B, Little P, Goodfellow PN. Absence of methylation of a CpG-rich region at the $5^{\prime}$ end of the MIC2 gene on the active $X$, the inactive $X$, and the $Y$ chromosome. Proc Natl Acad Sci USA 1988;85:5605-9

22 Kristiansen $M$, Helland A, Kristensen GB, Olsen AO, Lonning PE, BorresenDale AL, Orstavik KH. X chromosome inactivation in cervical cancer patients. Cancer Genet Cytogenet 2003;146:73-6.

23 Ganesan S, Silver DP, Greenberg RA, Avni D, Drapkin R, Miron A, Mok SC, Randrianarison V, Brodie S, Salstrom J, Rasmussen TP, Klimke A, Marrese C, Marahrens Y, Deng CX, Feunteun J, Livingston DM. BRCA1 supports XIST RNA concentration on the inactive $X$ chromosome. Cell 2002;111:393-405.

\section{BOOK REVIEW}

\section{Medical genetics}

Oxford Core Texts. (Pp 315; £22). Ian D Young, 2005. ISBN 0-19-856494-5.

The average medical student now receives something like 15 hours formal tuition in our specialty. Practices appear to vary widely from medical school to medical school as to what format that teaching takes, as to the nature and background of personnel offering teaching in medical genetics, not to mention the means by which students are examined In parallel with this fairly haphazard approach to teaching what is clearly considered to be a very minor subject of the medical school curriculum, the textbooks targeted at medical students have mushroomed. Not only has there been a proliferation of new authors entering this field but, as established observers will be aware, the size of the volumes offered expands with each passing edition. There is a theory in medical education that each lecturer thinks that students need to know about $80 \%$ of the knowledge the lecturer has themselves mastered. A passing glance at the ever increasing size of the textbooks in medical genetics aimed at the medical student market shows that geneticist authors are among the worst offenders in this particular category of sin.

Ian Young is a long established author and teacher of medical genetics in several medical schools worldwide. Few people are as conversant with the aims of medical genetics teaching as laid out by the ASHG and by the BSHG. The thoughtful foreword to this new book establishes clearly his view that the teaching of medical genetics should be founded firmly on basic principles and the demonstration of their clinical relevance. Such views are in stark contrast with the "bigger is better" approach so beloved of most geneticist authors. As a medical student, I clung firmly to the view that no book was the best option, but if one was necessary, let it be as small and cheap as possible. Perhaps student natures have changed maybe medical students nowadays want to own tomes that are all a minimum of 400 500 pages? If my recent experiences in this narrow jurisdiction are representative of global trends, students remain interested in smaller but clearly written textbooks.

This is a new book from an established and respected author. It comprises 14 chapters, each designed to be subject of a single lecture. Accordingly, the chapter titles and content are carefully chosen. The breadth of material covered is wide - impressively so and without omission of the essential principles. The style of writing is relaxed, as might be expected from a man who has given so much thought to these complex ideas that he knows how best to make them accessible to others. The pitfall of overfamiliarity with the material, which bedevils many experienced authors, is never a factor. There is no tiredness in the writing. The ideas naturally follow one another, their presentation fresh, accessible, and thoughtful. Appropriate figures, generally of a high quality, illuminate specific points. The diagrams, of which there are many, are clear, carefully chosen, high quality, and well presented. An interesting idea is to punctuate the text with specific case histories of celebrated examples of some point relevant to that chapter as well as to highlight and discuss a landmark original publication that has informed and moulded practice in relation to the issues under consideration. This is a very effective way of consolidating the principles in the text, practically showing the relevance, and reaffirming those principles again through the historic approach. Although placing a remarkable degree of burden upon the author, it is a highly successful approach to teaching. Who among us would have known of the contribution of "T-Boz Watkins", an apparently well known rap "artist" (my apostrophes) in the area of sickle cell disease? The author likes to surprise us but the breadth of reading and knowledge required to inform this style of writing is formidable.

This is a most impressive book, which achieves the clear sighted goals of its author and offers medical students enjoyable and interesting access to the core medical genetics curriculum without expecting them to practice as molecular biologists, cytogeneticists, or consultant clinical geneticists at the end of the exposure. At just under 300 pages, it offers achievable learning to students in a subject that, although minor to most medical schools, will probably be crucially important to most of tomorrow's doctors. Our specialty owes Ian Young a great debt for taking responsibility for making our subject accessible and enjoyable in this concise textbook. A remarkable achievement and one that should be warmly commended to all medical students and others seeking a basic understanding of the principles of genetics as applied to medicine.

W Reardon 